\title{
FORMATION AND ORIGINS OF THE DEVELOPMENT OF ENTREPRENEURIAL ACTIVITY IN UZBEKISTAN
}

\author{
Khadzhimuratov Abdukakhkhor Abdumutalovich \\ Doctor of Economic Sciences, Senior Lecturer of the Department of Management, \\ Fergana Polytechnic Institute. Uzbekistan.
}

\section{Становление и истоки развития предпринимательской деятельности в Узбекистане}

\author{
Хаджимуратов Абдукаххор Абдумуталович, \\ доктор экономических наук, \\ старший преподаватель кафедры “Менеджмент", \\ Ферганкий Политехнический институт. \\ Узбекистан.
}

Article DOI: https://doi.org/10.36713/epra7558 DOI No: 10.36713/epra7558

\begin{abstract}
Экономическая история Узбекистана достаточно изучена учеными-экономистами, однако ни в одном исследовании еще не рассматривался генезис предпринимательства экономической истории Узбекистана. Как показывает экономический анализ, основными предпосылками генезиса предпринимательства в Узбекистане являются, на наш взгляд, следующие общие условия:

1. Природно-климатические условия региона, создавшие исторические предпосылки функционирования азиатского способа производства.

2. Торгово-ростовщический капитал, развивавщийся на почве “Великого шёлкового пути”, проходившего одной из вех через территорию Узбекистана.

3. Эволюция рыночных отношений и экономический потенциал ре-гиона.

Во-первых, когда говорится о значений природно климатических условий, мы конечно не сможем рассмотреть всех аспектов. Считаем необходимым рассмотреть суть экономической стороны вопроса.

Историческая роль природно-климатических условий в основном отражается в так называемом “азиатском способе производства”. В предыдущем параграфе мы подробно рассмотрели суть вопроса и поэтому можем сделать вывод о том что азиатский способ производства выступает всеобщим условиям в накоплении капитала с древних времен для среднеазиатских государств и собственно для крупных землевладельцев. Это сложившееся условие испокон веков послужили исходной предпосылкой для развития рыночного хозяйства и, в свою очередь, предпринимательства.

Во-вторых, особое место занимает роль торгово-ростовщического капитала в генезисе предпринимательства стран Востока. Иными словами, торгово-ростовщический капитал сыграл своеобразную роль в развитии рыночных отношений и предпринимательства в Узбекистане.

Это обусловлено двумя разнообразными факторами, имеющими своеобразный характер. В отдельности его влияние на генезис предпринимательства. Так, по мусульманской религии разрешается вести коммерческую деятельность, это с одной стороны, а с другой - запрещается мусульманам заниматься ростовщичеством.
\end{abstract}




\section{EPRA International Journal of Research and Development (IJRD)}

Volume: 6 | Issue: 7 | July 2021

- Peer Reviewed Journal

Несмотря на эти положения эти два фактора имели своё место в экономической жизни Востока. Но нельзя сказать, что оба фактора почти равносильно и одинаковой мере способствовали развитию рыночных отношений и предпринимательства. Из них, как свидетельствуют древние источники, весьма превосходную роль играла, естественно, коммерция. Следовательно, есть необходимость выяснить особо активную роль торгового капитала.

Историко-экономическое развитие торгового капитала тесно была связана с так называемым “Великим шелковым путем”, проходившим через территорию Узбекистана, который испокон веков связывала Узбекистан с соседними странами Востока и другими странами зарубежья.

“Великий шёлковый путь” в своё время суммировал большое количество торговых караванных дорог, связывающих Китай с Передней Азией и Европой. Исследователи считают, что торговать с шелком с другими странами Китай начал, вероятно еще в V веке до нашей эры ${ }^{1}$. При этом особенно усилились торговые и культурные связи между Китаем и Средней Азией в 50-40-е годы II века до нашей эры. В Китае были завезены из Ферганы знаменитые в то время “небесные” кони и люцерны-корм для них, а также виноград и хлопок. В Фергану Согду и Бактрию из Китая проникло шелководство.

Позднее китайские купцы везли в Среднюю Азию шелк, золото и другие товары, среднеазиатские области отправляли в Китай изделия из стекла, драгоценные камни ,украшения. Характерен тот факт, что большинство купцов не стремилось пройти весь Шёлковый путь, а предпочитало обмениваться товарами на полпути, чаще всего в Средней Азии - в Хорезме, в Бухаре, Самарканде, а Коканд был центром рынка.

Торговые компании в странах Ближнего и Среднего Востока в средние века были очень распространены. Некоторые из них являлись мощными объединениеями купеческого капитала, державшими своих руках караванную торговлю в этих странах. Люди умели торговать, и они в те давние времена прекрасно понимали термины которые мы сегодня на XXI столетия пытаемся осмыслить, а при возможности - использовать в практике возрождающися ныне рыночных отношений.

Более того, много веков назад Запад узнал Восток благодаря рынку. И люди, занимающиеся торговлей, посредничеством, связывали не только страны, но и производителей. При том торговый капитал в среднеазиатском регионе развивался в основном на почти “Великого шёлкового пути”.

В связи с этим сложившиеся нынешние отношения в сфере торговли, оказания услуг, посредничестве и т.Д., имеет исторические корни. Например, посол китайского императора Вей Цзе побывавший в Самарканде в начале VII века в своих воспоминаниях о состоянии торговли в средней Азии писал так: “... Мальчиков с пяти лет начинают учить торговле. Когда они научатся читать, посылают изучать торговое дело”" действительно в исторических источниках имеются сведения о том, что в среднеазиатских странах малолетних детей с торговыми караванами посылали в далекие страны.

Поэтому следует отметить, что предприимчивость - это черта системы отношений закрепившиая, в ментальности народов Узбекистана.

Несомненно, это одновременно дало возможность развить ростовщичество с накоплением средств торговли и других сферах экономической жизни.

Довольно ясно, что “Великий шёлковый путь” сыграл особую роль в социально-экономическом развитии Востока, так как этот путь создавал благоприятные условия для развития крупного торгового капитала в регионе. При этом необходимо подчеркнуть, что “Великий шёлковый путь" и наряду с “азиатским способом производства" послужил одним из общих условий источников накопления капитала и в дальнейшем развитии рыночных отношений и прорастания предпринимательства. Здесь было бы целесообразно отметить, что купцы и ростовщики, предки народов Узбекистана, в своё время были мелкими бизнесменами. Только эволюция рыночных отношений преобразовала их последующие поколения в предприниматели в разных сферах, особенно в эпоху капитализма.

Вместе с тем исторически ростовщичества имело своё влияние в развитии рыночных отношений и предпринимательства, хотя мусульманская религия запрещала занимается ростовщичеством. Этого же придерживалось и Христианство. Это в тоже время в какой-то мере стимулировала предприимчивость там, особенно на Западе, где отсутствовали запреты.

Тем самым исторический генезис предпринимательства в Узбекистане тесно взаимодействовал с развитием торгово-ростовщического капитала. Иными словами, предпринимательства имело свои корни и в исторической, социальной и внешнеэкономической жизни Востока.

\footnotetext{
1 Неклесса Г. «Мусульманской торговле ... была свойственна горделивая осанка!»//Экономика и статистика. -1993 . - № 7. - с.29

${ }^{2}$ Цит. по: Юлдашев Н. Мыслители Востока о торговом деле // Экономика и статистика. - 1993 -№1 c. 58
} 


\section{EPRA International Journal of Research and Development (IJRD)}

Volume: 6 | Issue: 7 | July 2021

- Peer Reviewed Journal

В-третьих, в рассматриваемом процессе следует отметить особую роль эволюции рыночных отношений, которые отражаются в экономической географии региона. Следовательно, Генезис предпринимательства в Узбекистане обусловлен имеющей немаловажное значение экономической географии региона, где размещение производительных сил было тесно связано с исторически сложившимися условиями. Иными словами, развитие производительных сил всегда тесно взаимодействовала с производственными отношениями. Именно на этой почве прорастала предпринимательство как вид деятельности от зародышевой формы до самой зрелости.

Развитию предпринимательства способствовали исторические корни. Так в XVI-XV вв. территория Узбекистана была наиболее развитой частью Центральной Азии. Это была эпоха правления Тимура, великого полководца, с именем которого связывают расцвет экономической жизни Востока. В своё время он намного расширил круг своих владений, выйдя за пределы Центральной Азии. Тогда во многом поощрялась предприимчивость и социально-экономической жизни и создавались соответствующие условия для развития рыночных отношений.

В XVI - XVIII вв. на территории Узбекистана сложилось три государства: Бухарское, Хивинское и Кокандское ханства. К этому же периоду относится начало торговых и дипломатических отношений с Россией.

В это время наиболее промышленно-торговыми и культурными центрами являлись Ташкент, Самарканд, Бухара, Коканд, Хива, Маргелан, известные далеко за пределами Центральной Азии.

Так, хлопчатобумажные ткани производились в основном в Бухаре и Коканде шёлковые в Маргилане и Намангане. Производилась писчая бумага где центрами были Коканд и Самарканд. Металлообрабатывающее производство было сосредоточено, главным образом, в Намангане, производство чугунных изделий в Бухаре. Например, в Бухаре к 1842 году имелось шесть чугунолитейнных заводиков. Здесь производились сельскохозяйственные орудия и ядра для артиллерией. Сырьем являлся привозной из России чугун ${ }^{3}$. изделий.

В хозяйствах широкое распространение имело производство гончарных и керамических

Следует отметить, что только с двадцатых годов XIX века начинает образовываться зародыши текстильного производства в форме мануфактуры. Однако в это время господствующей формой промышленного производства ещё являлось ремесленно-кустарное с цеховым объединением и этот “средневековый” строй был главным препятствием для возникновения мануфактурного разделения труда. Ремесленное производство было сконцентрировано, главным образом, в городах, где ремесленники были объединены в цехи.

С этого периода на территории Узбекистана наметилась тенденция к постепенному расширению числа мелких местных рынков. Тем не менее, местные рынки ещё не объединились в единый национальный рынок. Мешала недостаточность развития товарно-денежных отношений, территориального разделения труда, специализация отдельных районов в производстве рыночного продукта.

Только к середине XIX века достаточным развитием ремесленного производства, образование промышленных центров и расширением внешнеэкономических связей сформировалась предпосылкой для создания единого среднеазиатского рынка.

Поэтому характерной чертой экономической жизни Средней Азии к середине XIX века является развитие товарно-денежных отношений.

Необходимо подчеркнуть, что нынешний опыт становления предпринимательства в экономике Узбекистана - это результат длительного процесса эволюции экономических отношений. Пойденный путь эволюции предпринимательства проходил через ряд этапов.

В экономической литературе имеется единственный подход к выделению этапов возникновения и развития предпринимательства в странах СНГ, относящийся к Узбекистану, в частности.

Согласно этому подходу создание центров научно-технической молодёжи по линии комсомола является исходным моментом возникновения предпринимательства и в связи с этим выделяется четыре этапа совпадающих только с эпохой социализма и далее ${ }^{4}$.

У нас другой подход, так как мы ищем корень предпринимательства в глубине экономической истории Узбекистана и связываем его с историческими корнями рыночных отношений. По нашему

\footnotetext{
${ }^{3}$ Бутенев. Заводское дело в Бухарии // Горный журнал. - Кн.Х. - Ч. IV. - СПб., 1842 - с.149

${ }^{4}$ Сайитбаев Ш.Д. Предпринимательство в аграрной сфере производства. - СПб.: Изд-во СПбУЭФ. 1993. c 24-26
} 


\section{EPRA International Journal of Research and Development (IJRD)}

Volume: 6 | Issue: 7 | July 2021

- Peer Reviewed Journal

убеждению, надо полагать что эволюции предпринимательства и рыночных отношений выделяются пять этапов. При этом критерием выделения этапов служит изменение господствующей формы собственности, соответственно, способа производства.

Так в эволюции предпринимательства Узбекистана можно выделить следующие этапы:

Первый этап - это период до второй половины XIX века, как исходный период отличающийся созданиями предпосылок и характеризующийся разбросанностью.

Второй этап - это период, охватывающий вторую половину XIX и начало XX веков, характеризуется широким распространением частного предпринимательства и рыночных отношений, причем в этапе классического капитализма.

Третий этап - это недолгий период НЭПа, когда изменение условий хозяйствования переориентировало предприимчивых людей в сторону необходимости заняться предпринимательством с большими на то возможностями.

Четвёртый этап соответствует периоду социализма, то есть после НЭПа до конца 80-х годов. Этот этап характеризуется господством государственного предпринимательства, где полностью отсутствует деятельность частного предпринимательства, причём предпринимательство как таковое, не получило официальное разрешение.

Последний пятый этап это нынешний период с конца 80-х годов прошлого века, когда идёт бурный процесс становления предпринимательства совершенно по-новому. Причём последний этап характеризуется цивилизованностью в отличие от прежних этапов. Именно на этом этапе, то есть в настоящее время, восстанавливаются исторические традиции, предприимчивости начинается по-новому заявлять о себе. в Узбекистане.

Следует достаточно охарактеризовать рассматриваемые этапы эволюции предпринимательства

Первый этап - это период до второй половины XIX века, смешивается во многом с общими условиями предпринимательства. Особенность исходного этапа заключается с тем, что корни предпринимательства закладываются именно на этом этапе. Поэтому генезис предпринимательства берёт начало в этом периоде, который, образно говоря, можно назвать зародышевым периодом, поскольку данное понимание вытекает из рассматриваемых общий условий предпринимательства, “азиатский способ производства”, “Великий шёлковый путь” и образование единого среднеазиатского рынка и т.д. - это те условия которые послужили как “инкубатором” для эволюционного развития предпринимательства и экономических отношений в целом в среднеазиатском регионе.

Следовательно, в рассматриваемый период, особенно в первую половину XIX века, в Средней Азии наблюдался некоторый экономический прогресс, который создал в дальнейшем благоприятные условия для бурного развития предпринимательской деятельности счёт расширение рыночных отношений. периодом

Второй этап развития предпринимательства в Узбекистане совпадает с колониальным

Во второй половине XIX века с присоединением Средней Азии к России создавались возможности для развития экономики региона. Так, распространились более передовые в рыночные формы хозяйства и общественных отношений.

Безусловно, произошли серьезные изменения в экономике в сторону капиталистического развития. При этом произошло развитие производительних сил края, возник рост промышленного производства, связанного с переработкой хлопка, то есть хлопкоочистительной, маслобойной и мыловаренной отраслей производства. Хотя это было одностороннее развитие производительних сил края, целиком подчиненное интересам экономики метрополии и носившее чисто колониальный характер. Поэтому развивались лишь те отрасли промышленности, которые занимались первичной переработкой колониального сельскохозяйственного сырья. Поэтому Средняя Азия, став производителем рыночного продукта -хлопка, постоянно втягивалась в мировой рынок.

Разумеется, присоединение Средней Азии к России дало значительный толчок для бурного развития предпринимательства и рыночных отношений. Тем не менее нельзя сделать общий вывод из этого, что историческая “судьба” и генезис предпринимательства в среднеазиатском регионе полностью зависела от российского капитала, поскольку историческая эволюция предпринимательства имеет свои глубокие корни (в зачаточном состоянии), то есть развивается до “присоединения” как мы выяснили.

Поэтому мы убеждены в том, что присоединение Средней Азии к России лишь ускорило этот процесс эволюции предпринимательства. Это связано, в первую очередь, с внедрением буржуазной формы собственности и других капиталистических отношений. 


\section{EPRA International Journal of Research and Development (IJRD)}

Volume: 6 | Issue: 7 | July 2021

- Peer Reviewed Journal

Вместе с тем наряду с отрицательными моментами невозможно отрицать прогрессивную сторону этого “присоединения". По этому поводу было бы целесообразно провести одну из многочисленных мнений, встречающихся в экономической литературе. Так, в своё время Вд.Лаврентьев отмечал, что: “Завоевание Туркестана предоставила неограниченные возможности молодому российскому капиталу, и особенно промышленному текстильному, в деле расширения рынков сбыта. При этом российский купеческий капитал не только не затрагивал “экономические основы азиатского производства", но и, наоборот, - мог расти и развиваться только на этой основе"5.

Несомненно, тут имеется в виду, что вывоз хлопчатобумажных и шелковых готових тканей в качестве своего непременного условия предполагают сохранение мелкой и мельчайшей домашней ткацкой промышленности, тесно связанных с сельским хозяйством.

Отрицательные стороны “присоединения” для экономики Туркестана состоят в её колониальном характере.

В связи с этим следует согласиться с существующим в научной литературе мнением о том, что колонизация послужила гигантским стимулятором развития российского предпринимательства ${ }^{6}$. Действительно, колонизация была бы невозможна без широкого развитого в русских людях чувства личности, предприимчивости, без навыков организации хозяйственной деятельности очень сложных условиях. При этом экономика Туркестана главным образом была нацелена на вывоз. А отрасли, удовлетворяющие запросы внутреннего рынка края, по своим масштабам стояли на втором плане.

Положительным является построение железных дорог, которые способствовали развитию предпринимательства и рыночных отношений в регионе. Так в конце XIX века была построена основная линия железной дороги региона, и этим занималось государство. С 1908 года начался новый этап строительства в котором участвовало частное предпринимательство.

В этом мероприятии выделялись такие предпринимательские фирмы как “Общества КокандНаманганской железной дороги” и “Общество Бухарской железной дороги” образованы в 1908 году.

Строительство железной дороги связывал отдельные районы Туркестана между собой. Население их стало более подвижным, ослабевала прикованность к своему месту жительства. Железнодорожное строительство, облегчая передвижение населения, способствовало разрушению территориальной замкнутости отдельных районов края. Естественно, это своеобразным путем способствовало и создавало возможность развития предпринимательства различных местах Туркестана.

При рассмотрении второго этапа эволюции предпринимательства в регионе прежде всего нужно отметить немаловажную роль деятельности местных предпринимателей. Например, первый хлопкоочистительный завод в Средней Азии был постоянно 1874 г. в г.Ташкенте предпринимателем В.П.Кузнецовым. В 1880 г. местный предприниматель Алимжан - ходжа Мухаммаджанов построил хлопкозавод в г.Андижане, в 1881 г. промышленник - Л.Югович -в г.Катта - Кургане.

В Ферганской области первое промышленное предприятие возникло в 1886 году на ст.Горчаково - хлопкозавод с 6 джинами и паровым двигателем в 25 л.с. Через 20-25 лет количество таких заводиков-предпринимателей резко увеличилось.

Среди местных богатых людей появились предприниматели, владельцы крупных фирм: Даутбаев, Ходжаев, Бузрукходжа, братья Вадьяевы, Потеляхов, Миркамил Мирмуминбаев в Ферганской области; Фузайлов, Калантаров, Хакимбаев в Самаркандской области; Юсуф Давыдов, братья Якущевы, Асадуллаев, Арифходжаева в Ташкенте. Одному только “Товариществу бр.Вадьяевых" на равных началах с “Андреевским товариществом” принадлежало 30 хлопкозаводов и 5 маслозаводов, Потеляхову - 10, Миркамил Мирмуминбаев - 4. Из 27 маслозаводов 5 принадлежало местным предпринимателям ${ }^{8}$.

Предпринимательские фирмы в основном занимались производством хлопка-сырца и хлопкоочистительной промышленностью и через них другими отраслями народного хозяйства.

По экономическому характеру более крупные предпринимательские фирмы на территории Узбекистана могут быть поделены на три основные группы:

1) “чистые” хлопковые фирмы, сосредоточивщие у себя в наибольших размерах и скупку хлопка-сырца его первичную промышленную переработку: “Т.Д. бр.Вадьяевых”, “Потеляховское

\footnotetext{
5 Лаврентьев Вл. Капитализм в Туркестане. - Л., 1930. - с. 12

${ }^{6}$ Черников Г.П. Предприниматель - кто он? Из опыта российского и зарубежного предпринимательства. - М.:Межд. отн., 1992. - с.80.

${ }^{7}$ Ибрагимов К.С. Так рождалось отрасль (из истории становления хлопкоочистительной промышленности Узбекистана). - Г.: Мехнат. 1989. - с.5

${ }_{8}^{8}$ Орлов П.А. Указатель фабрик и заводов окраин России: Царства Польского, Кавказа, Сибири и СреднеАзиатски владений. Материалы для фабрично-заводской статистики. - СПб. 1895. - с. 120-131
} 


\section{EPRA International Journal of Research and Development (IJRD) \\ Volume: 6 | Issue: 7 | July 2021 \\ - Peer Reviewed Journal}

торгово-промышленное товарищество”, акционированное Русско-азиатским банком накануне войны “Андреевское товарищество”. К этой группе относятся Торговый дом “Бр. Крафт” Торговый дом “Бр. Шлосберг”, Т.Д. “Симхаев”;

2) Торговые фирмы, хотя и занимающиеся скупкой сырца и его очисткой, но наряду с этим ведущие крупную торговлю мануфактурой и промышленными товарами как на внутреннем туркестанском рынке, так и с отдельными странами: Московское торгово-промышленного товарищество и Торгово-промышленное товарищество для торговли с Персией и Средней Азией. К этой группе можно отнести Туркестанское торгово-промышленное товарищество Юсуфа Давыдова в Ташкенте, Фузаилова в Самарканде, Сагателова в Мерве, Юсупбаев в Намангане и др.;

3) Промышленные текстильные фирмы, занимающиеся продажей и “попутно” скупкой хлопца-сырца и его очисткой на собственных и арендованных хлопкоочистительных заводах. К этой группе, кроме того, относятся Акционерное товарищество “Хлопок” - бывшая Лодзинское акционерное общество "Познанского".

Кроме того, имущество и капиталы торгового дома “Соловьев и К” находилось в расроряжении объединения предпринимателей - преимущественно из второй и третьей группы “Беш-бош”.

Первая группа объединяла 40 хлопкоочистительных и 6 маслобойных заводов (20\% и $18 \%$ общего числа).

Вторая и третьи группы - 28 хлопкоочистительных и 3 маслобойных (14\% и 9\% общего числа) $)^{9}$.

Следует отметить функционирования предпринимательских фирм в аграрном секторе, занимающихся выращиванием хлопка и других сельскохозяйственных культур. Например, “Среднеазиатское торгово-промышленное товарищество" и "Иски Ташкентского товарищества на паях", которые занимались выращиванием хлопчатника, фруктов, винограда и др. сельхозкультур и их местной переработкой.

Таким образом, начало XX века ознаменовалось значительным ростом предпринимательского движения. Это придало рост промышленности в Средней Азии, который характеризуется в таблице №1

Таблица 1

Развитие промышленности в отралях Туркестана вошедших в состав Узбекистан *

\begin{tabular}{|c|c|c|c|c|c|}
\hline Область & \multicolumn{5}{|c|}{ Число основанных предприятий } \\
\hline & До 1900 г. & $\begin{array}{c}\text { С } 1900 \text { по } \\
1910 \text { г. }\end{array}$ & $\begin{array}{c}\text { С } 1910 \text { по } \\
1914 \text { г. }\end{array}$ & неизвестно & всего \\
\hline Ферганская & 67 & 105 & 112 & 25 & 309 \\
\hline Сырь-Дарьинская & 50 & 80 & 47 & 6 & 183 \\
\hline Самаркандская & 54 & 38 & 20 & 5 & 117 \\
\hline ИТОГО & 171 & 223 & 179 & 36 & 609 \\
\hline
\end{tabular}

- $\quad$ Таблица составлена автором по данным источника ${ }^{10}$

Очевидно, что в пределах нынешнего XIX Узбекистана и в начале XX веков находились три области динамично развивающейся промышленностью: Ферганская, Сырь-Дарьинская и Самаркандская. В то время благодаря предпринимательскому движению совершенны крупны нововведения особенно в области промышленности. Построены новые заводы в этом регионе.

Так, если до 1900 г. было построено 171 предприятие, то за 10 лет (с 1910 до 1910 гг.) - 223, а за 4 последующих года - 179 предприятий. Уже к 1914 года на территории бывшего Узбекистана действовали 609 заводов, в том числе 220 хлопкоочистительных заводов, 27 маслобойный и 12 мыловарёных, а также 58 мукомольных, 22 кирпичных, 13 спиртоочистительных и т.д областей.

На этих заводах создавалось больше $80 \%$ стоимости валовой продукции промышленности

Нетрудно заметить, что на территории бывшего Туркестана существовало коммерческое, производственное и финансовое предпринимательство. По отраслям особое внимание заслуживает хлопкоочистительная и маслобойная промышленность. Характерной чертой развития этих отраслей промышленности в Туркестане в последующие годы перед революции являлось их интенсивное акционирование и проникновение банковского капитала уже не в заготовительные операции, а непосредственно в процессе производства.

\footnotetext{
9 Лаврентьев Вл. Указ. соч. - с. 62 .

10 Заорская В.В., Александров К.А. Промышленные заведения Туркестанского края. - Петроград, 1915 Вып. 1 - с. 17.
} 
Кроме того, было бы целесообразно прослеживать вышеперечисленные другие предпринимательские фирмы по формам деятельности.

Истоки предпринимательства показывают, что в основном существовали индивидуальное, частное, коллективное и государственное предпринимательство. Здесь индивидуальное предпринимательство функционировало в качестве кустарных промыслов и в коммерции.

Частное - единоличное владение собственностью в земледелии, животноводстве и цеховых объединениях - мануфактурах и строительстве и т.д.

Коллективное предпринимательство - в виде товариществ и акционерных обществ в разных отраслях производства, торговли и финансовой сфере.

Вместе с тем деятельность предпринимательских фирм была в зависимости от банковского капитала. Следовательно, у большинства почти половина, у конкретных значительная часть акций принадлежала банкам, что характерно для деятельности фирм, так как, кто не был связан с банковским капиталом, имел трудности реализации акций на именных предъявителей. Примером может служить деятельность “Иски Ташкентского товарищества на паях”, которая сталкивалас с этим препятствием и реализация паев шла с большими трудностями.

Характерно, что почти все акционерные общества Туркестана первоначально получали право выпуска только именных паев - получить разрешение на выпуск именных паев был гораздо легче, чем паев на предъявителя. Обладание акциями на предъявителя давало возможность фактического владения недвижимостью в Туркестане и лицам, которым это законом воспрещалось. Но привлечь в общество банковской капитал путем продажи именных паев было очень трудно чаще всего невозможно. Вот почему все АО Туркестана стремились получить право на выпуск предъявительских акций и обычно добивались своего.

При этом своё время существовал ряд нерешенных вопросов в законодательстве и в государственной поддержке, которые не давали возможности широко развиться предпринимательским фирмам. Из них главные препятствия были связаны с Положением управления края.

Согласно "Положению" частный капитал должен быть русским, русских подданных, но не иностранцев. Хотя в то время часть русских капиталов собственно в России работала мало.

На наш взгляд, местному предпринимательству необходимо было привлечь частный капитал, безразлично, русских, евреев, армянских, узбекских или иностранных предпринимателей, необходимо только все эти капиталы ставить в такие условия, чтобы не было и следов ростовщичества, политиканства и чтобы средний подданный-предприниматель мог также укрепиться и численно увеличится, как это наблюдается в большинстве промышленных районов Европейской России. Несомненно, утверждением данного мнения является другой пример деятельности местных предпринимателей братьев Вадьяевых, которые сумели в свое время преодолеть эти препятствия и развивались благоприятно.

Вместе с тем, что было ещё препятствие для предпринимательских фирм, связанных с нерешенностью земельно-водных отношений, то есть отсутствие водного закона в Туркестане, что не давало возможности активно работать предпринимателям в сельском хозяйстве.

Что касается вопроса о государственной поддержке, она почти отсутствовала, кроме железнодорожного строительства. Это мероприятие, конечно, осуществлялось в государственных интересах. Поэтому, выпущенные на предприятиях акции этих фирм, были гарантированы правительством.

Естественно, нельзя отрицать факт некоторые поддержки фирм, когда деятельность фирм сходится с интересами правительства. Это особенно связано с хлопководством.

Между тем, очевидно, что характерно для данного этапа - это, распространение так называемого нами “заводского предпринимательства”. Именно этот вид производственного предпринимательства имел окраски для других видов его на протяжении прошлого столетия.

Наряду с этим этапом процесса развития предпринимательства следует упомянуть, что с победой Социалистической революции началась в перемена в развитии предпринимательства, возник новый этап эволюции предпринимательства.

Так с учреждением Высшего Совета Народного Хозяйства Советская власть приступила к национализации отраслей промышленности. Соответственно 28 февраля 1918 года Совнарком Туркестана принял декрета конфискации хлопка, 5 марта - о национализации предприятий хлопкоочистительной и маслобойной промышленности. С теми решениями постепенно ликвидировалось предпринимательство, не только как соответствующий класс, но даже и как тип старого хозяйственного поведения. 
Следует упомянуть некоторые особенности третьего периода, этапа оживления предпринимательской деятельности во время НЭПа, что имеет большое значение для сегодняшнего дня.

В период НЭПа предпринимательство стало использоваться для восстановления экономики. Возрождение предпринимательской деятельности в концепции НЭПа рассматривалась как вынужденная необходимость, отступление перед капитализмом.

На этом этапе этапе стало заметным развитие предпринимательства на всех уровнях. Тем более, что предпринимательскими по сути своей функциями прежде всего стала заниматься государство.

В первую очередь, речь идет о концессии. Вместе с тем были распространены аренда, кооперация, акционирование, командитные товарищества и т.д.

Вместе с тем, невозможно упустить из виду функционирование мелкотоварного производства в Узбекистане. В регионе широко развивались кустарные промыслы, которыми в дореволюционном Туркестанском крае занимались свыше 45\% хозяйств. В то время более чем 50 тыс. кустарноремесленных мастерских трудились около 110 тыс. человек.

С НЭПом увеличилось количество занятых мелкой промышленности и развитие мелкотоварного производства и в Узбекистане это шло стремительными темпами. Если она 1925-29 годах стоимость валовой продукции государственной промышленности в регионе увеличилась с 105,8 до 305,2 млн. руб., то есть примерно в 3 раза, то кустарная промышленность без больших капитальных вложений опережала государственную в 6,5, а промысловая кооперация - почти в 12 раз.

В 1929 году в Ферганском округе насчитывалось около 37 тыс. кустарей и рабочих мелких промышленных предприятий, в т.ч. 22 тыс. в городах и 15 тыс. - на селе; в Андижанском районе соответственно - 26,3; 13,0; 13,3 тыс.; в Ташкентском - 17,0; 13,0; 4,0 тыс.; Хорезмском - 11,7; 3,0; 8,7; Бухарском 11,2; 4,1; 7,1 тыс.; Сурхандарьинском округе- 6,5; 0,4; 6,1; тыс. человек ${ }^{11}$.

Развитие мелких и кустарно - ремесленных предприятий, как правило, обеспечивала сохранение национально-традиционных сфер производства и стремление коренного населения в индустриальное производство.

Очевидно, многообразие форм собственности открывало простор для развития предпринимательства. Более того, в годы НЭПа создавались благоприятные предпосылки для активизации предпринимательства. Этому способствовали два обстоятельства: денационализация мелких предприятий и законодательное разрешение учредительской деятельности. Всё это движение только постепенно погубилось, начиная с “принудительной кооперации” в 30 годах, которая функционировала до 90-х годов ХХ века.

Новый этап развития предпринимательства совпал с развитием социализма. Следовательно, этот этап отличается тем, что в хозяйственной жизни главная роль предпринимательской деятельности отводилась государству, коллективное предпринимательство недооценивалось, а частное предпринимательство имело место только в “теневой” экономике. Причём господствовала только государственная форма собственности.

По нашему убеждению, что право собственности не является существенным признаком предпринимательства. Исходя из этого можно сказать, что предпринимательство функционирует независимо от формы собственности. Когда говорим о частном предпринимательстве, конечно при этом должна быть частная собственность.

Это подтверждает то мнение, что в условиях социализма, явно противопоказанной предпринимательству административно-командной системы было много предприимчивых людей не только в Узбекистане, но и в других соответствующих республиках, сумевших несмотря на сковывающую хозяйственную жизнь жёсткую и мелочную регламентацию, постоянное давление государства проявлять экономическое творчество чтобы добиваться высоких результатов.

Все эти рассуждения дает возможность осмыслить положение о том, что в целом на протяжении социалистического хозяйствования предпринимательство в экономической жизни Узбекистана в принципе в том или ином деформированном виде существовало всегда.

Надо отметить, что впервые после НЭПа предпринимательство в советской экономике получило официальное признание лишь к концу, 80-х годов прошлого века и в связи с этим начался новый этап.

Принятый в ноябре 1986 г. Закон “Об индивидуально-трудовой деятельности” определил правила работы частного предприятия, но составлен он так, что не стимулировал предпринимательство. Этот закон не только определял, что частная деятельность не может быть основным занятием и не только может служить альтернативной работе в гос-секторе, но и не запрещал использование наемного

\footnotetext{
11 Абдуллаева Т. Промышленность Узбекистана. Особенности развития в период НЭПа // Экономика и статистика. - 1993. - №2 - c.60.61
} 


\section{EPRA International Journal of Research and Development (IJRD)}

Volume: 6 | Issue: 7 | July 2021

- Peer Reviewed Journal

труда, а также обязывал заинтересованных лиц получать лицензии. Часто трудно получить эти лицензии. Подобным образом в принятом в феврале 1987 г. Указе “О создании кооперативов по бытовому обслуживанию населения” содержалось важное ограничение, согласно которому кооперативы могут быть созданы только с разрешения местных правительственных Комиссии, государственных предприятий или организаций. Закон 1988 г. “О кооперативах” в большей степени отвечал интересам негосударственного предпринимательства, но в нём проводилась грань между социалистическим предпринимательством и капиталистом. Последующее законодательство другими способами ограничивало предпринимательство, в частности, запрещая или ограничивая возможность создания кооперативов в отдельных отраслях экономики, разрешая местным органам власти определять максимальную цену продукции кооперативов и взимать специальные налоги с их доходов.

Следует сказать, что сегодняшнее представление о необходимости предпринимательской деятельности складывалось в течение длительного времени эволюции и естественно, что предпринимательская деятельность со временем изменилась в зависимости от уровня производительных сил, отношений собственности, особенно в конце 80 -х годов при нескольких попытках введения новых форм хозяйствования.

Разумеется, что постепенно под влиянием менявшегося правительственного курса страны того периода жизнь привела “управленцев” к осмыслению необходимости перехода к рыночной экономике, подобно той, которая давно функционирует в развитых странах мира.

Таким образом, современное предпринимательство в экономике, Узбекистана имеет свою исторические корни из далёких времён. Так, нынешняя предприимчивость в ментальности его народов от рассматриваемых истоков предпринимательства и рыночных отношений, безусловно, будет приобретать все большее значение для будущего социально-экономического развития.

В связи с этим необходимо глубоко проанализировать нынешний этап становления предпринимательства в экономике Узбекистана в дальнейших исследованиях.

\section{Список использованной дитературы}

1. Хаджимуратов А.А. Становление предпринимательства в Узбекистане СПб, Изд -во СПб УЭФ,1996

2. Лаврентвев В. Капитализм в Туркестане Л.1930.

3. Бутенев. Заводское дело в Бухаре // Горный журнал, СПб., 1842., с.149.

4. Ибрагимов К.С. Так рождалась отрасль., Т.: Мехнат, 1989.

5. Заорская В.В. , Александер К.А. Промышленные заведения Туркестанского края.- Петроград., 1915. вылуск 1.

6. Абдуллаева Т. Промышленность Узбекистана. Особенности развития в период НЕПа // Экономика и статистика.- 1993.

7. Юлдашева Н.А. Антикризисная стратегия на предприятиях легкой промышленности. Приоритетные векторы развития промышленности и сельского хозяйства: материаль II Международной научнопрактической конференции. Том III. - Макеевка. 2019 2. 11 апрел. С.341-346. https://scholar.google.com/scholar?oi=bibs\&cluster $=13208487116094681718 \&$ btnI $=1 \&$ hl $=r u$

8. Yuldasheva NA (2018) Method of diagnostics of the enterprise in the system of anti-crisis management. ISJ Theoretical \& Applied Science, 04 (60): 248-252. https://dx.doi.org/10.15863/TAS.2018.04.60.45

9. Шакирова Ю.С., Ащуров М.С., Турдибеков О.И. Тенденции формирования многоукладной экономики в Узбекистане // Бюллетень науки и практики. Т. 5. №12, 2019. https://doi.org/10.33619/2414-2948/49/35

10. Шакирова Ю.С., Хонкелдиева Г.Ш. Перспективы инновационного развития корпораций в электроэнергетической отрасли. Известия Ошского технологического университета, №3, 2019 г. 